\title{
Accompanying the Primary Grocery Shopper Is Positively Related to Requests for Purchase of Fruits \& Vegetables in Third \& Fourth Grade Students
}

\author{
Jill Keith, Ardith Brunt, Sherri Stastny, Nandita Bezbaruah \\ North Dakota State University, Fargo, ND, USA \\ Email: jill.keith@ndsu.edu, nandita.bezbaruah@mnstate.edu, sherri.stastny@ndsu.edu, \\ ardith.brunt@ndsu.edu
}

Received 16 July 2015; accepted 4 August 2015; published 7 August 2015

Copyright (C) 2015 by authors and Scientific Research Publishing Inc.

This work is licensed under the Creative Commons Attribution International License (CC BY). http://creativecommons.org/licenses/by/4.0/

\section{(c) (i) Open Access}

\begin{abstract}
Consumption of fruits and vegetables is important for growth and development yet intake remains below recommended levels in children in the US. The purpose of this study was to determine whether children accompanying the primary grocery shopper impacts requests for fruit and vegetables and if those children requesting fruits and vegetables like to consume them on a daily basis. A cross-sectional survey design of matched pairs of third- and fourth-grade students and their parents/guardians in an urban Midwest school district was utilized. Third- and fourth-grade participants who asked for fruits and vegetables were more likely to accompany the primary grocery shopper and more prone to liking these key foods as part of their regular diet. Grocery shoppers should consider taking children along when food shopping, emphasizing strategies to find a variety of fruits and vegetables.
\end{abstract}

\section{Keywords}

Fruits and Vegetables, Grocery Shopper, School-Age Children, Food Requests, Food Preferences

\section{Introduction}

Fruits and vegetables are important sources of nutrients in childhood as well as adulthood and are an essential part of a well-planned diet. Healthy dietary intake (including meeting recommendations for fruit and vegetable intake) is important for growth and development including maintaining a healthy weight and preventing obesity, 
overweight, and subsequent chronic diseases [1]. Health behaviors, including dietary intake, during the years of growth and development can influence health in adulthood, since poor dietary habits in childhood often continue into adulthood [2] [3].

Fruit and vegetable intake remains below recommended levels in children and adults in the United States [4]-[8]. The current Dietary Guidelines for Americans recommend 1.5 cups of fruit and 2.5 cups of vegetables per day for an 1800 calorie food pattern intended for children 9 to 13 years of age [9]. Less than $25 \%$ of children between the ages of 9 and 12 years consume recommended servings of fruits and vegetables each day [10].

Parental knowledge of recommendations related to fruit and vegetable intake, promotion of healthy foods by parents or caregivers (such as fruits and vegetables), and parents' health attitudes and food involvement positively influence children's eating patterns [11]-[14]. In addition, the types of foods parents procure for consumption at home are influenced by parental nutritional knowledge and health attitudes [15] [16] and availability of fruits and vegetables at home enables higher consumption [17]-[20].

There are multiple influences on dietary behavior and food choices including biological (taste, hunger, and satiety), social-affective context (social conditioning, parenting practices), intra- and inter-personal determinants (beliefs, attitudes, family relationships), social and environmental factors (availability, accessibility), and economic considerations (price, education, and income) [19] [21]-[23]. These factors, including the person-related determinant of child food preferences, affect food purchasing patterns of parents of school-age children [21] [24]. Because parents are the gatekeepers for food availability in the home, determining factors that may increase parental purchasing intentions of fruits and vegetables can provide valuable information for nutrition educators [25].

Parents, or caregivers, who fill the role of primary grocery shopper, determine the foods available at home and ultimately, what to purchase. Therefore, the purchasing decisions of the primary grocery shopper will influence the availability of fruits and vegetables for consumption. This study utilized social-cognitive theory to determine whether children accompanying the primary grocery shopper will impact requests for fruit and vegetables and if those children requesting purchase of fruits and vegetables like to consume fruits and vegetables on a daily basis. Researchers hypothesized those children who asked the primary grocery shopper to purchase fruits and vegetables would be with parents/guardians more often in the grocery store. Researchers also hypothesized that children who asked for more fruits and vegetables would like to eat fruits and vegetables every day.

\section{Methods}

\subsection{Sample}

Participants in the study included third and fourth-grade students enrolled at Midwest elementary schools and their parent/guardians. Participants were recruited from four randomly selected schools of eight in a US Midwest school district. Random selection of schools was completed via cluster sampling [26]. Of 475 distributed surveys, 233 (49\%) were returned by matched pairs of parent/guardians and students during spring, 2009. Missing data for either children or parent/guardian responses resulted in the elimination of an additional seven surveys. There were 226 paired surveys included in the analysis. Sample size minimum was not calculated prior to distribution of the surveys.

\subsection{Procedure}

A previously validated questionnaire (using intra-class correlation coefficients, Cronbach's $\alpha$, and Spearman correlations) for examining the factors that influence intake of fruits and vegetables from the child's perspective [27] was adapted and pilot-tested before finalization for the study. This survey was provided for child participants. The 10-item student survey included five questions pertaining to fruit and five identical questions specific to vegetables. Student consumption and availability for fruits or vegetables was assessed using a 5-point scale from strongly agree to strongly disagree and yes/no questions, and likelihood of parental purchase of fruit or vegetables was assessed using a scale from always to never. The parent survey was developed after a literature review of identified factors that influence food choices [15] [28]-[32]. The 8-item parent survey included demographic questions, frequency of children accompanying parents in the grocery store on a 5-point scale from always to never, and rank-order regarding factors that determine purchasing decisions. The developed parent survey is presented in Table 1. Both student survey and parent survey were pilot tested and modified prior to 
Table 1. Parent/guardian questionnaire.

1) How many of your children are currently enrolled in $3^{\text {rd }}$ and $4^{\text {th }}$ grade?

Boy(s) __ Age Girl(s)___ Age

2) Relationship to the child/children who is participating in the study

$\begin{array}{ll}\text { Mother } & \text { Father } \\ \text { Stepmother } & \text { Stepfather } \\ \text { Grandmother } & \text { Grandfather } \\ \text { Legal guardian } & \text { Legal guardian }\end{array}$

3) Racial or ethnic background
White African American
Hispanic
Native American
Asian American

Others (please specify)

4) Education

Some high school

High school/GED

2-Year College Degree

Some college

4-Year College Degree

Master's Degree or higher

5) Marital status

Single (never married) Married Separated Divorced Widowed

6) How often are your child/children with you in a grocery store while purchasing fruits and vegetables (fresh/frozen)? Always Usually Sometimes Rarely Never

7) If you have had packages of fruits or vegetables with the picture of a cartoon character like Sponge Bob or Dora the Explorer on it at home, has your child/children eaten more of the fruits and vegetables from these packages?

Yes No We don't have packages at home with cartoon characters

8) What determines your purchasing decision when it comes to fruits and vegetables? (Please rank them in order, 1 meaning the most important factor and 8 meaning the least important factor)

- Taste

- Nutrition

— Family likes and dislikes

— Children's likes and dislikes

- Availability

- Convenience

- Cost

— Others (please specify)

finalization for the study. Pilot testing included eight $3^{\text {rd }}$ and $4^{\text {th }}$ grade students and ten parents of students, all with similar background as participants, from another school in the district not participating in the study. The pilot school was located in the same district and had similar demographics to participating schools.

Survey packets, which included the child survey, parent survey, and consent forms, were distributed by classroom teachers. Students returned the completed surveys to the school, along with the signed parental permission and child assent forms. While participation in the study was voluntary, stickers were provided to students who returned the survey packet to school (whether completed or incomplete). The university Institutional Review Board and the school district approved the study protocol. All participants provided written informed consent and child assent as required for IRB approval.

\subsection{Statistical Analysis}

Demographic information was summarized using descriptive statistics. In order to normalize the distribution of the data related to accompanying the primary grocery shopper, this question was re-scaled through collapsing from five-point categories (always, usually, sometimes, rarely, and never) to two-point scale (always/usually and sometimes/rarely/never). Correlation analysis was performed between children who asked their parents to buy fruits and vegetables and whether children accompanied parents for grocery shopping (based on the two-point scale). Since there were two groups, independent sample t-test analysis was used to compare children who asked or did not ask their parents to buy fruits and vegetables and their preference for liking to eat fruits and vegetables every day. Data for correlational and t-test analysis was assessed for normality using histogram analysis. Differences in demographic variables were not included in the analysis. Statistical analyses were carried out using SPSS 21.0 (IBM SPSS Statistics for Windows, Version 21.0. Armonk, NY: IBM Corp, 2012). The statistical significance was defined as $\mathrm{p}<0.05$. 


\section{Results}

Parent/guardian participants in the study $(\mathrm{n}=226)$ were primarily female $(83 \%)$ and White $(90 \%)$. A majority of respondents were married (80\%) and had a two- or four-year college degree (63\%). Demographics for parent/ guardian participants are presented in Table 2 . Student participants $(n=226)$ were primarily fourth-graders (74\%; 26\% third-graders) and White (90\%).

Frequency data for children accompanying the primary grocery shopper indicated respondents had children with them in the grocery store “always” (11\%), "usually” (36\%), “sometimes” (45\%), "rarely” (7\%), and “never” (1\%). Frequency data for grocery store shopping is presented in the Figure 1. Descriptive statistics showed more children asked for fruits (85\%) than vegetables (67\%) and that the number of children who generally liked to eat fruits at home (on a scale of 1 to 5 with 1 being strongly agree) was higher than the number who liked to eat vegetables ( $\mathrm{M}=1.97$ and $\mathrm{M}=2.20$, respectively).

Correlation analysis indicated a significant positive relationship between children who asked for fruits and whether they were with parents in the grocery store always/usually or sometimes/rarely/never $(r=0.175$, $\mathrm{p}<$ $0.01)$ as well as those who requested vegetables $(r=0.150, p<0.05)$. In addition, children who asked for fruits were significantly positively related to children who asked for vegetables $(r=0.601$, $p<0.01$ ). Correlation analysis is displayed in Table 3.

Children who asked or did not ask their parents to buy fruits and vegetables were compared on their preference for liking to eat fruits and vegetables every day. Children who asked for fruit from the person who does the grocery shopping were more likely to like fruit on a daily basis (on a scale of 1 to 5 with 1 being strongly

Table 2. Demographic characteristics of parent/guardians of third- and fourth-grade students $(n=226)$.

\begin{tabular}{cccc}
\hline Characteristic & Category & N & $\%$ \\
\hline Gender & Male & 39 & 17 \\
& Female & 187 & 83 \\
Race & White & 203 & 90 \\
& Non-white & 23 & 10 \\
Marital status & Single & 17 & 8 \\
& Married & 181 & 80 \\
& Separated & 5 & 2 \\
Education & Divorced & 23 & 10 \\
& High school diploma or less & 23 & 25 \\
& Some college & 56 & 23 \\
& 2 year college degree & 53 & 40 \\
\hline
\end{tabular}

*Some college is defined as schooling beyond a high school diploma but less than a 2 or 4-year college degree.

Table 3. Correlation analysis among third and fourth-grade students.

\begin{tabular}{cccc}
\hline & $\begin{array}{c}\text { Grocery store with parents } \\
\text { (always/usually) }\end{array}$ & Asked for fruit & Asked for vegetables \\
\hline $\begin{array}{c}\text { Grocery store with parents } \\
\text { (always/usually) }\end{array}$ & 1.00 & $0.175^{* *}$ & $0.150^{*}$ \\
Asked for fruit & $0.175^{* *}$ & 1.00 & $0.601^{* *}$ \\
Asked for vegetables & $0.150^{*}$ & $0.601^{* *}$ & 1.00 \\
\hline
\end{tabular}

${ }^{*}$ Correlation is significant at the 0.05 level; ${ }^{* *}$ correlation is significant at the 0.01 level. 


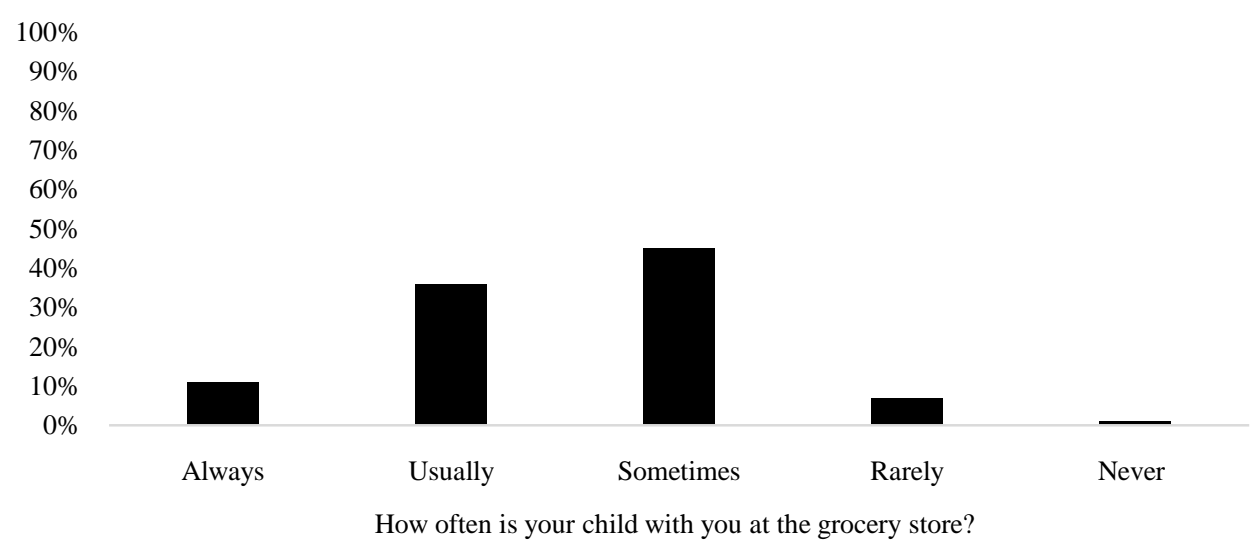

Figure 1. Frequency of accompanying the primary grocery shopper in third- and fourth-grade students $(n=226)$.

agree) than children who did not ask $(\mathrm{M}=1.87$ and $\mathrm{M}=2.66$, respectively; $\mathrm{t}(224)=-4.38, \mathrm{p}<0.01)$. Children who asked for vegetables were also more likely to like vegetables on a daily basis than the group of children who did not ask $(\mathrm{M}=1.88$ and $\mathrm{M}=2.91$, respectively; $\mathrm{t}(224)=-7.23, \mathrm{p}<0.01)$.

\section{Discussion}

Since fruit and vegetable intake remains below recommended levels in both children and adults, it is critical that nutrition professionals identify factors that influence parental purchase of fruits and vegetables. Purchase of fruits and vegetables is the first step in getting fruits and vegetables into the home. Understanding this process will help educators to develop programs that will promote behavior change such as increasing fruit and vegetable consumption. In order to develop programs that promote behavior change such as increased consumption of fruits and vegetables, understanding influencing factors on dietary behaviors is critical [21] [33].

This research revealed that third and fourth-grade student participants accompanying the primary grocery shopper was positively correlated with requests to purchase fruits and vegetables. This finding was consistent with the researcher's hypothesis and provides valuable insight for nutrition education efforts that include a focus on consumer shopping habits. Children's requests may influence grocery store purchases, and this study revealed that third and fourth-grade student participants being present in the grocery store environment with the primary grocery shopper was significantly correlated with child requests for fruits and vegetables. Increased purchasing of fruits and vegetables promotes availability for consumption in the home. Home food availability of fruits and vegetables is associated with improved intake in children and adolescents [17]-[20].

Accompanying the primary grocery shopper may pose other dietary challenges such as the increased likelihood of children's requests for sweets and snacks instead of fruits and vegetables [24] and the challenge of trying to restrain child requests rather than fulfill child desires [34]. In addition, children may be more likely to be influenced by advertising techniques often used in food purchasing environments including cartoon characters on food packaging [35]. However, previous research has shown that children are interested in the grocery store environment (particularly the produce section) and that the grocery store can be a potential learning opportunity for children [24]. Additionally, young children may influence the food purchasing, preparation, and consumption of healthy foods such as fruits and vegetables if those foods are encouraged or sampled in a childcare or school environment [14] [36]. For nutrition educators, including methods for promoting healthy food intake and education using the food purchasing environment as well as encouragement of fruit and vegetable intake in formal childcare and school settings may be beneficial for dietary behavior outcomes [37].

The findings of the current study also indicated that third and fourth-grade student participants who requested the purchase of fruits and vegetables also liked to eat fruits and vegetables every day. Whether this was due to parental intake of fruits and vegetables, parent education levels, food involvement, or exposure to fruits and vegetables at school or home was not determined from this study. However, previous studies have linked intake of fruits and vegetables (amount and variety) with parents who have high levels of food involvement (the level of importance of food in a person's life), knowledge of fruit and vegetable recommendations, promotion of 
healthy foods, and health attitudes [11]-[14]. In addition, those parents who prioritize natural or whole, nutrient-dense, high-fiber, low calorie foods have children with higher intake of nutrient-dense foods such as fruits and vegetables [38]. This provides insight for nutrition educators to plan education and programming to include a focus on parental knowledge, food involvement, and promotion techniques for use with children.

\section{Limitations}

Limitations to this study included limited racial/ethnic diversity in the study sample since $90 \%$ of participants were White. However, this racial/ethnic percentage is similar to the demographics of the city's population. In addition, participants included only third- and fourth-grade students and parent/guardians resulting in less variation due to physical and cognitive development of the child participants. Future studies may include students from a variety of grade levels and additional qualitative and quantitative questions for parents regarding why the child accompanied the parent to the grocery store and the impact of children's food preferences on food purchasing patterns.

\section{Conclusion}

Overall, the findings of the study indicate third and fourth-grade student participants accompanying the primary grocery shopper to the food purchasing environment is positively related to whether they ask for fruits and vegetables to be purchased. Parent/guardians who are the primary grocery shopper may be influenced by children accompanying them when it comes to fruit and vegetable purchases. In addition, it appears that third and fourth-grade student participants who are requesting the purchase of fruits and vegetables are more apt to eat them on a daily basis. Including children in the food purchasing environment may have a positive influence on fruit and vegetable procurement and should be considered in nutrition education efforts. Healthcare and school professionals should encourage families to consider taking children along when food shopping, emphasizing strategies to find a variety of fresh, frozen, and canned fruits and vegetables.

\section{Acknowledgements}

This research received no specific grant from any funding agency in the public, commercial, or not-for-profit sectors.

\section{Conflict of Interests}

The authors declare that there is no conflict of interest.

\section{References}

[1] Gross, S., Pollock, E. and Braun, B. (2010) Family Influence: Key to Fruit and Vegetable Consumption among Fourth and Fifth-Grade Students. Journal of Nutrition Education \& Behavior, 42, 235-241. http://dx.doi.org/10.1016/j.jneb.2009.05.007

[2] Cohen, S., Janicki-Deverts, D., Chen, E. and Matthews, K. (2010) Childhood Socioeconomic Status and Adult Health. Annals of the New York Academy of Sciences, 1186, 37-55. http://dx.doi.org/10.1111/j.1749-6632.2009.05334.x

[3] Fisk, C., Crozier, S., Inskip, H., Godfrey, K., Cooper, C., Robinson, S., et al. (2011) Influences on the Quality of Young Children's Diets: The Importance of Maternal Food Choices. British Journal of Nutrition, 105, 287-296. http://dx.doi.org/10.1017/S0007114510003302

[4] Brug, J., Tak, N., te Vedle, S., Bere, E. and De Bourdeaudhuij, I. (2008) Taste Preferences, Liking, and Other Factors Related to Fruits and Vegetables Intakes among School-Children: Results from Observational Studies. British Journal of Nutrition, 99, S7-S14. http://dx.doi.org/10.1017/S0007114508892458

[5] Casagrande, S., Wang, Y., Anderson, C. and Gary, T. (2007) Have Americans Increased Their Fruits and Vegetables Intake? The Trends between 1988 and 2002. American Journal of Preventive Medicine, 32, 1-7. http://dx.doi.org/10.1016/j.amepre.2006.12.002

[6] Larson, N., Neumark-Sztainer, D., Hannan, P. and Story, M. (2007) Trends in Adolescent Fruits and Vegetables Consumption 1999-2004: Project EAT. American Journal of Preventive Medicine, 32, 147-150. http://dx.doi.org/10.1016/j.amepre.2006.10.011

[7] Middaugh, A., Fisk, P., Brunt, A. and Rhee, Y. (2012) Few Associations between Income and Fruit and Vegetable 
Consumption. Journal of Nutrition Education \& Behavior, 44, 196-203. http://dx.doi.org/10.1016/j.jneb.2011.10.003

[8] United States Department of Agriculture [USDA] (2014) USDA Fruit and Vegetable Program.

http://www.ers.usda.gov/topics/food-nutrition-assistance/child-nutrition-programs/usda-fruit-and-vegetable-program.as $\mathrm{pX}$

[9] USDA (2010) Dietary Guidelines for Americans, 2010. http://www.cnpp.usda.gov/Publications/USDAFoodPatterns/USDAFoodPatternsSummaryTable.pdf

[10] Guenther, P., Dodd, K., Reedy, J. and Krebs-Smith, S. (2006) Most Americans Eat Much Less than Recommended amounts of Fruits and Vegetables. Journal of the American Dietetic Association, 106, 1371-1379. http://dx.doi.org/10.1016/j.jada.2006.06.002

[11] Blanchette, L. and Brug, J. (2005) Determinants of Fruit and Vegetable Consumption among 6-12-Year-Old Children and Effective Interventions to Increase Consumption. Journal of Human Nutrition \& Dietetics, 18, 431-443. http://dx.doi.org/10.1111/j.1365-277X.2005.00648.X

[12] Boutelle, K., Birkeland, R., Hannan, P., Story, M. and Neumark-Sztainer, D. (2007) Associations between Maternal Concern for Healthful Eating and Maternal Eating Behaviors, Home Food Availability, and Adolescent Eating Behaviors. Journal of Nutrition Education \& Behavior, 39, 248-256. http://dx.doi.org/10.1016/j.jneb.2007.04.179

[13] Gibson, E., Wardle, J. and Watts, C. (1998) Fruit and Vegetable Consumption, Nutritional Knowledge and Beliefs in Mothers and Children. Appetite, 31, 205-228. http://dx.doi.org/10.1006/appe.1998.0180

[14] Ohly, H., Pealing, J., Hayter, A., Pettinger, C., Pikhart, H., Watt, R. and Rees, G. (2013) Parental Food Involvement Predicts Parent and Child Intakes of Fruits and Vegetables. Appetite, 69, 8-14. http://dx.doi.org/10.1016/j.appet.2013.05.003

[15] Ball, K., Crawford, D. and Mishra, G. (2006) Socio-Economic Inequalities in Women’s Fruits and Vegetables Intakes: A Multilevel Study of Individual, Social and Environmental Mediators. Journal of Public Health Nutrition, 9, 623-630. http://dx.doi.org/10.1079/phn2005897

[16] Hupkens, C., Knibbe, R. and Drop, M. (2000) Social Class Differences in Food Consumption: The Explanatory Value of Permissiveness and Health and Cost Considerations. European Journal of Public Health, 10, 108-113. http://dx.doi.org/10.1093/eurpub/10.2.108

[17] Ding, D., Sallis, J., Norman, G., Saelens, B., Harris, S., Kerr, J., Rosenberg, D., Durant, N. and Glanz, K. (2012) Community Food Environment, Home Food Environment, and Fruit and Vegetable Intake of Children and Adolescents. Journal of Nutrition Education \& Behavior, 44, 634-638. http://dx.doi.org/10.1016/j.jneb.2010.07.003

[18] Larson, N.I., Neumark-Sztainer, D.R., Harnack, L.J., Wall, M.M., Story, M.T. and Eisenber, M.E. (2008) Fruit and Vegetable Intake Correlates during the Transition to Young Adulthood. American Journal of Preventive Medicine, 35, 33-37. http://dx.doi.org/10.1016/j.amepre.2008.03.019

[19] Rasmussen, M., Krolner, R., Klepp, K.-I., Lytle, L., Brug, J., Bere, E. and Due, P. (2006) Determinants of Fruit and Vegetable Consumption among Children and Adolescents: A Review of the Literature. Part I: Quantitative Studies. International Journal of Behavioral Nutrition \& Physical Activity, 3, 22. http://dx.doi.org/10.1186/1479-5868-3-22

[20] Spurrier, N.J., Magarey, A.A., Golley, R., Curnow, F. and Sawyer, M.G. (2008) Relationships between the Home Environment and Physical Activity and Dietary Patterns of Preschool Children: A Cross-Sectional Study. International Journal of Behavioral Nutrition \& Physical Activity, 5, 31. http://dx.doi.org/10.1186/1479-5868-5-31

[21] Contento, I. (2011) Nutrition Education: Linking Research, Theory, and Practice. 2nd Edition, Jones and Bartlett Publishers, LLC, Sudbury, MA.

[22] McClain, A.D., Chappuis, C., Nguyen-Rodriguez, S.T., Yaroch, A.L. and Spruijt-Metz, D. (2009) Psychosocial Correlates of Eating Behavior in Children and Adolescents: A Review. International Journal of Behavioral Nutrition \& Physical Activity, 6, 54. http://dx.doi.org/10.1186/1479-5868-6-54

[23] van der Horst, K., Oenema, A., Ferreira, I., Wendel-Vos, W., Giskes, K., van Lenthe, F. and Brug, J. (2007) A Systematic Review of Environmental Correlates of Obesity-Related Dietary Behaviors in Youth. Health Education Research, 22, 203-226. http://dx.doi.org/10.1093/her/cyl069

[24] O’Dougherty, M., Story, M. and Stang, J. (2006) Observations of Parent-Child Co-Shoppers in Supermarkets: Children's Involvement in Food Selections, Parental Yielding, and Refusal Strategies. Journal of Nutrition Education \& Behavior, 38, 183-188. http://dx.doi.org/10.1016/j.jneb.2005.11.034

[25] Zarnowiecki, D.M., Dollman, J. and Parletta, N. (2014) Associations between Predictors of Children’s Dietary Intake and Socioeconomic Position: A Systematic Review of the Literature. Obesity Reviews, 15, 375-391. http://dx.doi.org/10.1111/obr.12139

[26] Cottrell, R. and McKenzie, J. (2011) Health Promotion \& Education Research Methods: Using the Five-Chapter Thesis/Dissertation Model. 2nd Edition, Jones and Bartlett Publishers, LLC, Sudbury, MA. 
[27] De Bourdeaudhuij, I., Klepp, K.I., Due, P., Rodrigo, C.P., de Almeida, M.D.V., Wind, M., et al. (2005) Reliability and Validity of a Questionnaire to Measure Personal, Social and Environmental Correlates of Fruit and Vegetable Intake in 10-11-Year-Old Children in Five European Countries. Public Health Nutrition, 8, 189-200. http://dx.doi.org/10.1079/PHN2004673

[28] Cassady, D., Jetter, K.M. and Culp, J. (2007) Is Price a Barrier to Eating More Fruits and Vegetables for Low-Income Families? Journal of the American Dietetic Association, 107, 1909-1915. http://dx.doi.org/10.1016/j.jada.2007.08.015

[29] Guthrie, J., Lin, B., Reed, J. and Stewart, H. (2005) Understanding Economic and Behavioral Influences on Fruits and Vegetables Choices. Amber Waves, 3, 36-41.

[30] Hosler, A.S., Rajulu, D.T., Fredrick, B.L. and Ronsani, A.E. (2008) Assessing Retail Fruits and Vegetables Availability in Urban and Rural Underserved Communities. Prevention of Chronic Disease, 5, 1-9.

[31] McGee, B.B., Richardson, V., Johnson, G.S., Thornton, A., Johnson, C., Yadrick, K., Ndirangu, M., et al. (2008) Perceptions of Factors Influencing Healthful Food Consumption Behavior in the Lower Mississippi Delta: Focus Group Findings. Journal of Nutrition Education \& Behavior, 40, 102-109. http://dx.doi.org/10.1016/j.jneb.2006.12.013

[32] Søndergaard, H.A. and Edelenbos, M. (2007) What Parents Prefer and Children Like: Investigating Choice of Vegetable-Based Food for Children. Journal of Food Quality \& Preference, 18, 949-962. http://dx.doi.org/10.1016/j.foodqual.2007.03.009

[33] Brug, J., Oenema, A. and Ferreira, I. (2005) Theory, Evidence and Intervention Mapping to Improve Behavioral Nutrition and Physical Activity Intervention. International Journal of Behavioral Nutrition \& Physical Activity, 2, 1-7. http://dx.doi.org/10.1186/1479-5868-2-2

[34] Haselhoff, V., Faupel, U. and Holzmuller, H. (2014) Strategies of Parents and Children during Shopping for Groceries. Young Consumers: Insight and Ideas for Responsible Marketers, 15, 3-3.

[35] Bezbaruah, N. and Brunt, A. (2012) The Influence of Cartoon Character Advertising on Fruit and Vegetable Preferences of 9- to 11-Year Old Children. Journal of Nutrition Education \& Behavior, 44, 438-441. http://dx.doi.org/10.1016/j.jneb.2011.03.139

[36] Tande, D., Niemeier, B.S., Hwang, J.H., Stastny, S. and Hektner, J.M. (2013) Intervention Changes Fruit and Vegetable Intake among Preschoolers in Pilot Study. Journal of Nutrition Education \& Behavior, 45, S58-S59. http://dx.doi.org/10.1016/j.jneb.2013.04.155

[37] Niemeier, B., Tande, D., Hwang, J., Stastny, S. and Hektner, J. (2010) Using Education, Exposure, and Environments to Increase Preschool Children's Knowledge of Fruit and Vegetables. Journal of Extension, 48, 1-5.

[38] Roos, E., Lehto, R. and Ray, C. (2012) Parental Family Food Choice Motives and Children's Food Intake. Journal of Food Quality \& Preference, 24, 85-91. http://dx.doi.org/10.1016/j.foodqual.2011.09.006 